\title{
Use of Probiotics to Control Aflatoxin Production in Peanut Grains
}

\author{
Juliana Fonseca Moreira da Silva, ${ }^{1,2}$ Joenes Mucci Peluzio, ${ }^{2}$ \\ Guilherme Prado, ${ }^{3}$ Jovita Eugênia Gazzinelli Cruz Madeira, ${ }^{3}$ \\ Marize Oliveira Silva, ${ }^{3}$ Paula Benevides de Morais, ${ }^{2}$ Carlos Augusto Rosa, \\ Raphael Sanzio Pimenta, ${ }^{2}$ and Jacques Robert Nicoli ${ }^{1}$
}

\author{
${ }^{1}$ Departamento de Microbiologia, Instituto de Ciências Biológicas, Universidade Federal de Minas Gerais, Bloco J, $4^{\circ}$ Andar, \\ Sala 171, Avenida Antônio Carlos 6627, CP 486, Pampulha, 31270-901 Belo Horizonte, MG, Brazil \\ ${ }^{2}$ Laboratório de Microbiologia Ambiental e Biotecnologia, Universidade Federal do Tocantins, ALC No. 14 Campus Universitário, \\ Avenida NS 15 Bloco II Sala 05, 77.001-090 Palmas, TO, Brazil \\ ${ }^{3}$ Fundação Ezequiel Dias, Laboratório de Micologia e Micotoxinas, Rua Conde Pereira Carneiro 80, \\ 30510010 Belo Horizonte, MG, Brazil
}

Correspondence should be addressed to Raphael Sanzio Pimenta; biorapha@yahoo.com.br

Received 15 April 2015; Revised 11 June 2015; Accepted 16 June 2015

Academic Editor: Aldo Corsetti

Copyright (C) 2015 Juliana Fonseca Moreira da Silva et al. This is an open access article distributed under the Creative Commons Attribution License, which permits unrestricted use, distribution, and reproduction in any medium, provided the original work is properly cited.

\begin{abstract}
Probiotic microorganisms (Saccharomyces cerevisiae var. boulardii, S. cerevisiae UFMG 905, and Lactobacillus delbrueckii UFV $\mathrm{H} 2 \mathrm{~b} 20$ ) were evaluated as biological control agents to reduce aflatoxin and spore production by Aspergillus parasiticus IMI 242695 in peanut. Suspensions containing the probiotics alone or in combinations were tested by sprinkling on the grains followed by incubation for seven days at $25^{\circ} \mathrm{C}$. All probiotic microorganisms, in live and inactivated forms, significantly reduced $A$. parasiticus sporulation, but the best results were obtained with live cells. The presence of probiotics also altered the color of $A$. parasiticus colonies but not the spore morphology. Reduction in aflatoxin production of 72.8 and $65.8 \%$ was observed for $S$. boulardii and $S$. cerevisiae, respectively, when inoculated alone. When inoculated in pairs, all probiotic combinations reduced significantly aflatoxin production, and the best reduction was obtained with S. boulardii plus L. delbrueckii (96.1\%) followed by S. boulardii plus S. cerevisiae and $L$. delbrueckii plus $S$. cerevisiae (71.1 and 66.7\%, resp.). All probiotics remained viable in high numbers on the grains even after 300 days. The results of the present study suggest a different use of probiotics as an alternative treatment to prevent aflatoxin production in peanut grains.
\end{abstract}

\section{Introduction}

Peanut (Arachis hypogaea) is one of the major food crops cultivated throughout the tropics and subtropical regions and its annual world production is of approximately thirty-eight million tons [1]. However, this grain is very susceptible to mycotoxin contamination, especially by aflatoxins. Aflatoxins are secondary metabolites produced by three filamentous fungal species: Aspergillus flavus, A. parasiticus, and A. nomius [2, 3]. The aflatoxins can be classified as $B_{1}, B_{2}, G_{1}$, and $G_{2}$ according to their fluorescence under ultraviolet light and molecular weight and strains of $A$. parasiticus can produce all of them [4]. The $B_{1}$ aflatoxin is recognized by the International Agency for Research on Cancer as a group 1 carcinogenic substance, whereas aflatoxins $B_{2}, G_{1}$, and $G_{2}$ are classified as possible carcinogenic substances [5].

Aflatoxin contamination in peanuts is a great economical and public health concern [6] and many studies search for efficient methodologies capable of controlling filamentous fungal growth in pre- and postharvest. Use of GRAS 
(Generally Regarded as Safe) substances and antagonistic microorganisms has been tested with some success [79]. Antagonism is one of the most important phenomena observed in microecological relationships, and the principal mechanism responsible for the beneficial effect of probiotic yeasts and bacteria. Probiotics are defined by the Food and Agriculture Organization/World Health Organization [10] as "live microorganisms which when administered in adequate amounts confer a health benefit on the host." An interesting possibility of using the antagonistic ability of probiotics would be to impair growth and/or aflatoxin production by phytopathogenic fungi during storage of grains.

Shetty and Jespersen [11] reported that Saccharomyces cerevisiae and lactic acid bacteria (LAB) can reduce the toxic effects of mycotoxins in foods by absorption on their cell walls. The LAB are known as predominant participants in many industrial food processes, especially in vegetables, meats, and dairy fermentations, where they can prevent contamination by harmful microorganisms. Saccharomyces cerevisiae is the most important microorganism responsible for production of alcoholic beverages and biofuel. Both LAB and Saccharomyces (particularly S. cerevisiae var. boulardii) have already been described for their use as probiotics [12-14].

S. cerevisiae (UFMG 905) reduced the translocation levels of pathogens, promoted the host immunomodulation, decreased the mortality and helped in the preservation of liver tissue and gut barrier integrity, and reached population levels potentially functional in the gastrointestinal tract in mice [15-17]. Lactobacillus delbrueckii (H2b20) protected germfree mice against infection with pathogens and stimulated the cytokines production. Due to this, these microorganisms were elected to be tested as food protectors in this study [18].

The objective of this work was to evaluate the capabilities of three probiotic microorganisms (two strains of S. cerevisiae and one of $L$. delbrueckii) to reduce the sporulation and aflatoxin production by $A$. parasiticus in peanuts.

\section{Materials and Methods}

2.1. Peanut Grains. Autoclaved peanuts grains, cultivar IAC Caiapó, available from Instituto Agronômico de Campinas were used. The grains had medium size, brownish color, high oil content, and no aflatoxin presence and were produced in the $2009 / 2010$ crop.

2.2. Microorganisms. Aspergillus parasiticus IMI 242695 isolated from contaminated food products and aflatoxin producer $\left(B_{1}, B_{2}, G_{1}\right.$, and $\left.G_{2}\right)$ was obtained from the International Mycological Institute (UK). Saccharomyces boulardii 17 was obtained from MERCK/SA (Rio de Janeiro, RJ, Brazil), S. cerevisiae UFMG 905 pertained to the Collection of Microorganisms and Cells of Federal University of Minas Gerais (UFMG), and Lactobacillus delbrueckii H2b20 was isolated from a healthy newborn and pertained to the culture collection of the Laboratório de Ecologia e Fisiologia de Microorganismos (Departamento de Microbiologia, Universidade Federal de Minas Gerais, Belo Horizonte, MG, Brazil).

\subsection{Sample Preparation: Growth, Resuspension, and Dilution}

2.3.1. Aspergillus parasiticus IMI 242695. Spores were obtained as described by Prado et al. [19]. Spore concentration was determined using a hemocytometer and adjusted to $1 \times$ $10^{6}$ spores $/ \mathrm{mL}$ in $50 \mathrm{~mL}$ of $0.1 \%$ Tween 80 .

2.3.2. Yeasts. Saccharomyces boulardii and $S$. cerevisiae UFMG 905 cells were obtained by culture on YM agar medium ( $2 \%$ glucose, $0.5 \%$ peptone, $0.3 \%$ malt extract, $0.3 \%$ yeast extract, and $2 \%$ agar) incubated for $24 \mathrm{~h}$ at $37^{\circ} \mathrm{C}$. Colonies were collected and suspended in $0.1 \%$ Tween 80 and the cell concentration was determined using a hemocytometer and the suspension was adjusted to $1 \times 10^{8}$ cells $/ \mathrm{mL}$ in a final volume of $50 \mathrm{~mL}$.

2.3.3. Lactobacillus delbrueckii. Bacterial cells were obtained by culture on de Man, Rogosa and Sharpe (MRS) agar medium incubated for $24 \mathrm{~h}$ at $37^{\circ} \mathrm{C}$ in aerobic static conditions. Colonies were collected and suspended in $0.1 \%$ Tween 80 and the cell concentration was determined using a hemocytometer and the suspension was adjusted to $1 \times 10^{8}$ cells $/ \mathrm{mL}$ in a final volume of $50 \mathrm{~mL}$.

2.4. Biological Control Assays. Autoclaved peanuts grains were used in the following eleven experimental groups ( $15 \mathrm{~g}$ in each): (1) first positive control: grains inoculated with $2.5 \mathrm{~mL}$ of $A$. parasiticus spore suspension and $2.5 \mathrm{~mL}$ of $0.1 \%$ Tween 80; (2, 3 and 4) negative controls: grains inoculated with $2.5 \mathrm{~mL}$ of each yeast or bacterial suspension plus $2.5 \mathrm{~mL}$ of $0.1 \%$ Tween 80 ; (5, 6 and 7$)$ simple antagonistic tests: grains inoculated with $2.5 \mathrm{~mL}$ of each yeast or bacterial suspension plus $2.5 \mathrm{~mL}$ of $A$. parasiticus spore suspension; (8) second positive control: grains inoculated with $2.5 \mathrm{~mL}$ of $A$. parasiticus plus $5 \mathrm{~mL}$ of $0.1 \%$ Tween 80 ; $(9,10$, and 11 ) combined antagonistic tests: grains inoculated with $2.5 \mathrm{~mL}$ of combined yeast or bacterial suspension in a factorial association for inoculation with two microorganisms ( $L$. delbrueckii + S. cerevisiae; S. boulardii + S. cerevisiae; and $S$. boulardii + L. delbrueckii) plus $2.5 \mathrm{~mL}$ of $A$. parasiticus spore suspension. All the inoculations were performed by sprinkling of grains with microbial suspensions followed by incubation for seven days at $30^{\circ} \mathrm{C}$.

2.5. Aflatoxin Quantification. The aflatoxin quantification was performed by fluorodensitometry at $365 \mathrm{~nm}$ using a fluorodensitometer (model CS9301, Shimadzu Corp., Kyoto, Japan). Concentration of aflatoxin $B_{1}$ was calculated by comparing the fluorescent intensity of sample spots with known standard amounts spotted on the same plate in the range from 0.8 to $0.88 \mathrm{ng}$ [20].

2.6. Microbial Cell Viability on Peanut Grains. To determine the evolution of microbial cell viability on peanuts during storage, $15 \mathrm{~g}$ of peanut grains was placed in an plastic film covered Erlenmeyer flask $(250 \mathrm{~mL})$ and soaked with $2.5 \mathrm{~mL}$ of each yeast or bacterial suspension and the mixture was incubated at $25^{\circ} \mathrm{C}$. At regular time intervals (weekly until 21 
TABle 1: Spores production of A. parasiticus IMI 242695 after incubation for seven days at $30^{\circ} \mathrm{C}$ with S. boulardii, S. cerevisiae UFMG 905 , and L. delbrueckii UFV H2b20, in viable or inactivated forms. $\mathrm{SR}=$ spore reduction, $\mathrm{AP}=A$. parasiticus.

\begin{tabular}{|c|c|c|c|c|}
\hline \multirow{2}{*}{ Assays } & \multicolumn{2}{|c|}{ Live cells } & \multicolumn{2}{|c|}{ Inactivated cells } \\
\hline & Average $^{1}$ deviation & SR (\%) & Average $^{1}$ deviation & SR $(\%)$ \\
\hline Positive control (AP) & $11.9 \mathrm{Aa} \pm 0.37$ & - & $11.9 \mathrm{Aa} \pm 0.37$ & - \\
\hline S. boulardii $\times \mathrm{AP}$ & $6.4 \mathrm{Ba} \pm 0.36$ & 46,3 & $9.0 \mathrm{Cb} \pm 0.42$ & 24,9 \\
\hline S. cerevisiae $\times \mathrm{AP}$ & $6.5 \mathrm{Ba} \pm 0.68$ & 45,8 & $9.2 \mathrm{Bb} \pm 0.41$ & 22,7 \\
\hline L. delbrueckii $\times \mathrm{AP}$ & $4.9 \mathrm{Ba} \pm 0.89$ & 59,3 & $10.2 \mathrm{Bb} \pm 0.49$ & 14,0 \\
\hline
\end{tabular}

${ }^{1}$ Different letters (uppercased letters for columns and lowercased letters for rows) indicate significant differences according to Tukey's test $(P<0.05)$.

days and monthly until 330 days), viable cell counts were performed as follows. Three inoculated grains were introduced in three assay tubes containing $10 \mathrm{~mL}$ of sterile saline. The tubes were agitated for approximately $30 \mathrm{~s}$, and an aliquot of the supernatant was submitted to serial decimal dilution up to $10^{-5}$ in saline sterile solution. Then, $50 \mu \mathrm{L}$ of each dilution was plated onto MRS or YM agar media for Lactobacillus and yeasts counts, respectively, and incubated at $30^{\circ} \mathrm{C}$ for $48 \mathrm{~h}$. After incubation, viable cell number was determined and the results expressed as decimal logarithm of colony forming units per grain ( $\log _{10} \mathrm{CFU} /$ grain). Culture inoculation and counting were automatically performed by spiral plate and colonies counter (IUL Instruments, Barcelona, Spain).

2.7. In Vitro Antagonism Assay. To evaluate a possible in vitro antagonism of yeast and Lactobacillus probiotics against A. parasiticus, the agar double layer diffusion test was described by Tagg et al. [21] with some modifications. The antagonistic effect was evaluated using live and inactivated cells of each probiotic. In the assay using live cells (Assay 1) Petri dishes containing adequate medium (agar MRS or YM for bacteria or yeasts, resp.) were inoculated with $10 \mu \mathrm{L}$ of yeast or bacterial suspension in the center and incubated at $37^{\circ} \mathrm{C}$ during $24 \mathrm{~h}$. After incubation, $3.5 \mathrm{~mL}$ of MEA medium (1.2\% malt extract, $2 \%$ agar) supplemented with $10 \mu \mathrm{L}$ of $A$. parasiticus spore suspension was spread onto the agar surface and the dishes were incubated at $25^{\circ} \mathrm{C}$ for seven days. In the assay using inactivated cells (Assay 2), after inoculation on the center of the Petri dish, the yeast or bacterial spot was killed by chloroform vapor exposition for $20 \mathrm{~min}$. Then, Petri dishes were held open in a laminar flow hood until complete removal of residual chloroform and the dishes were treated as in Assay 1. After incubation, presence of growth inhibition zone and alterations in appearance of the phytopathogen were observed.

2.8. Determination of Number and Morphology of A. parasiticus Spores. This determination was performed with the same Petri dishes used for the in vitro antagonism assay described above. The spore count was done as follows: $10 \mathrm{~mL}$ of $0.1 \%$ Tween 80 and ten glass beads were added to each plate, and after shaking, the supernatant was transferred to a conical tube $(50 \mathrm{~mL})$. After homogenization, spore concentration in the supernatant was determined using a hemocytometer. The results were expressed as spores $\mathrm{mL}$. To evaluate morphological alterations, $20 \mu \mathrm{L}$ from each suspension was stained with cotton blue and visualized using an optical microscopy (Leica
DM 750), and the images were captured and analyzed with the Leica microsystems DFC 425 software.

2.9. Statistical Analysis. All the experiments followed a randomized design with five replicates each. Data were submitted to Kolmogorov-Smirnov test of normality and then compared by variance analysis and Tukey test at $5 \%$ of significance. Statistical analysis was performed using the Sisvar 5.3 software (UFLA, Lavras, MG, Brazil).

\section{Results and Discussion}

Saccharomyces boulardii, S. cerevisiae UFMG 905, and L. delbrueckii were able to reduce significantly $A$. parasiticus sporulation as shown in Table 1. These reductions were observed with the utilization of both viable and inactivated yeasts and bacteria, but a higher reduction was obtained with live cells.

Additionally, in these in vitro experiments with the use of viable and inactivated microorganisms, a color alteration in A. parasiticus appearance was observed when compared to the control group (olive green to yellow) (Figures 1(a) $-1(\mathrm{~g})$ ). This alteration, due to the reduction in spore production, represents a considerable vantage for the use of the tested probiotics since this effect can reduce the pathogen dispersion in stored grains. On the other hand, there was no inhibition of the mycelium growth as well as no structural modifications of A. parasiticus spores which remained globose, rough (with spines), and hyaline.

In relation to the ability to reduce spore production, there was no statistical significant difference among the three viable microorganisms, despite the tendency to a better result for the Lactobacillus. Similar results were observed by Onilude et al. [22] using six lactic acid bacteria (LAB) (L. fermentum OYB, L. fermentum RS2, L. plantarum MW, L. plantarum YO, L. brevis WS3, and Lactococcus spp. RS3) to control the growth of two strains of A. parasiticus and four of A. flavus (all aflatoxigenic). L. plantarum YO strain significantly inhibited the vegetative growth and sporulation of all phytopathogens tested. These findings demonstrate the antifungal activity of some Lactobacillus, and the inhibition was possibly related to a $\mathrm{pH}$ reduction and/or a nutrient competition of the culture medium. Bueno et al. [23] evaluated the capacity of two Lactobacillus species (L. casei CRL 431 and L. rhamnosus CRL, 1224) to reduce the growth of three strains of A. flavus, and they observed a decreased growth of the phytopathogens when cultivated in association with the Lactobacillus strains (reduction of mycelium dry weight of $73 \%$ and $85 \%$ with CRL 


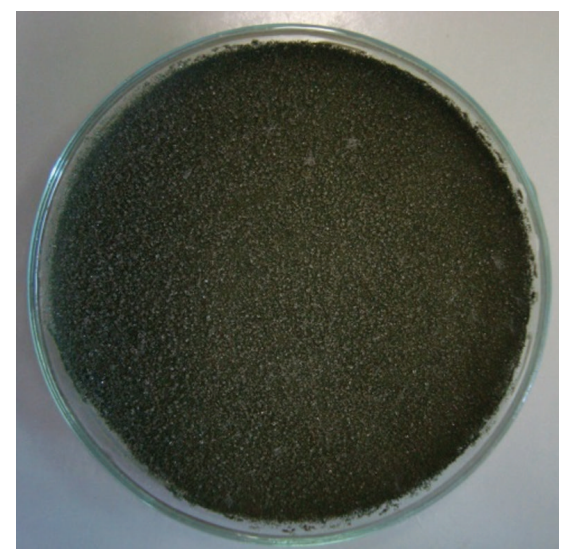

(a)

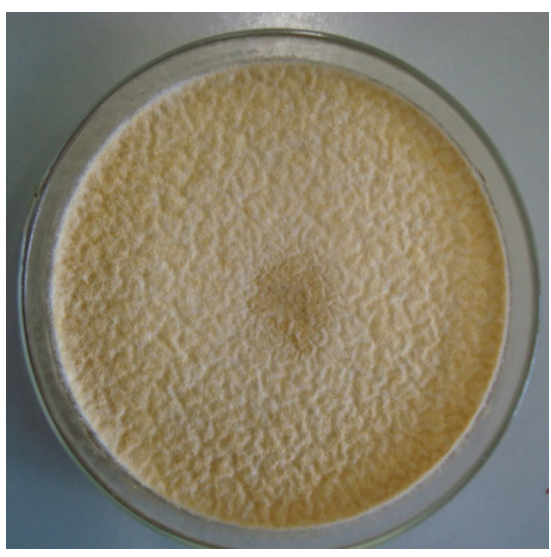

(b)

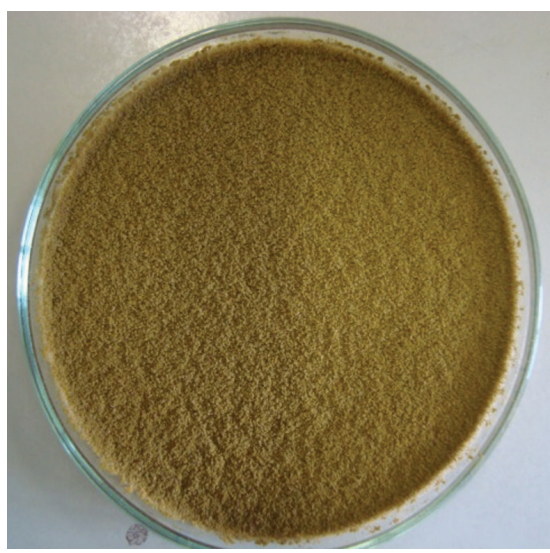

(e)

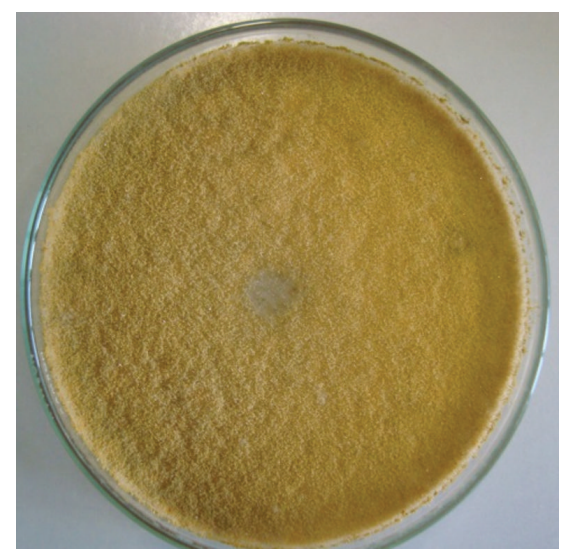

(c)

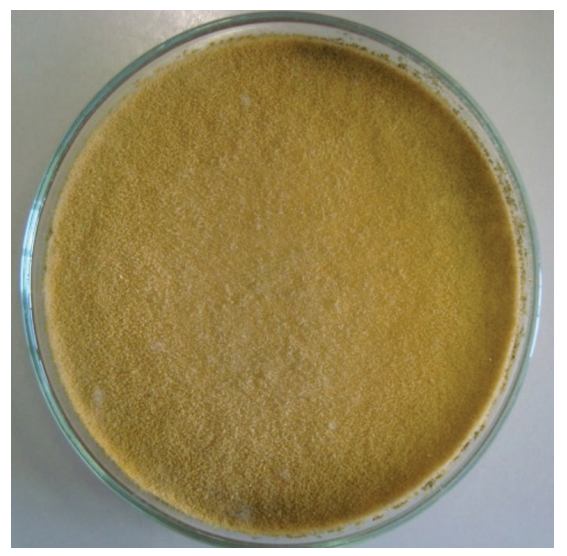

(f)

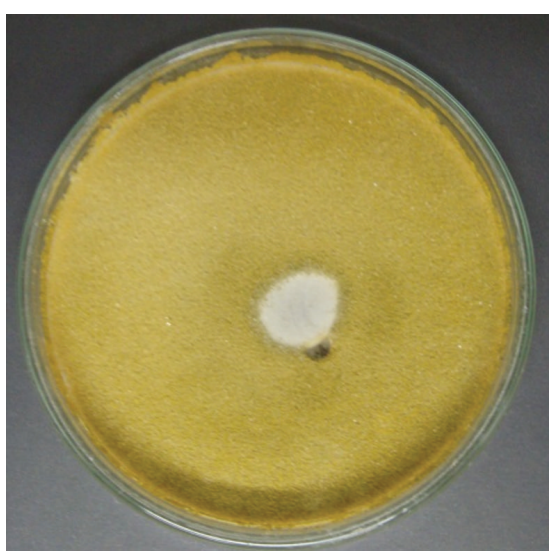

(d)

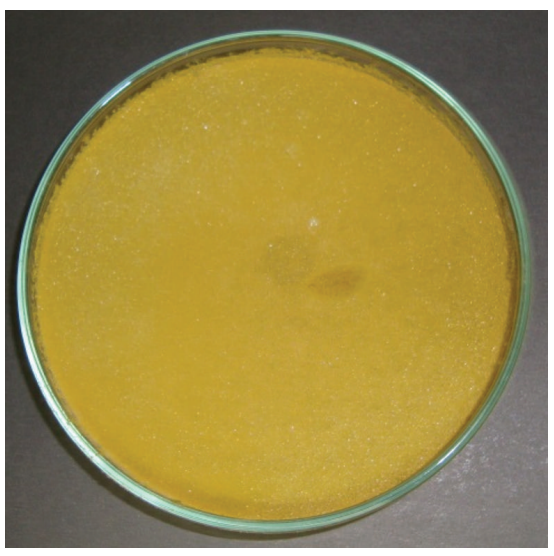

(g)

FIgUre 1: Positive control: A. parasiticus IMI 242695 (10 $\mu \mathrm{L}$ at $10^{6}$ spores $/ \mathrm{mL}$ ) incubated for seven days at $30^{\circ} \mathrm{C}$ in semisolid malt agar (a). Group 1, live antagonistic cells $\left(10 \mu \mathrm{L} 10^{8}\right.$ cells $\left./ \mathrm{mL}\right)$ incubated for seven days at $30^{\circ} \mathrm{C}$. L. delbrueckii $\times$ overlapping culture $\left(10 \mu \mathrm{L} 10^{6}\right.$ spores $/ \mathrm{mL}$ of A. parasiticus IMI 242695) (b); S. boulardii $\times$ overlapping culture (c); S. cerevisiae strain UFMG $905 \times$ overlapping culture (d). Group 2 , antagonistic cells inactivated by chloroform vapors $\left(10 \mu \mathrm{L}\right.$ a $10^{8}$ cells $\left./ \mathrm{mL}\right)$ incubated for seven days at $30^{\circ} \mathrm{C}$. L. delbrueckii $\times$ overlapping culture $\left(10 \mu \mathrm{L} 10^{6}\right.$ spores/mL of $A$. parasiticus IMI 242695) (e); S. boulardii $\times$ overlapping culture (f); S. cerevisiae strain UFMG $905 \times$ overlapping culture (g).

43 and CRL 1224 strain, resp.). Similar results were observed by Muñoz et al. [24], when three LAB and one S. cerevisiae strain were tested for antagonistic effects against $A$. nomius under different incubation conditions. After three days of coculture, $75 \%, 40 \%, 36 \%$, and $20 \%$ of growth inhibition of $A$. nomius were observed for L. rhamnosus O236, L. fermentum ssp. cellobiosus 408, L. fermentum 27A, and S. cerevisiae, respectively. However, these antagonistic effects against 


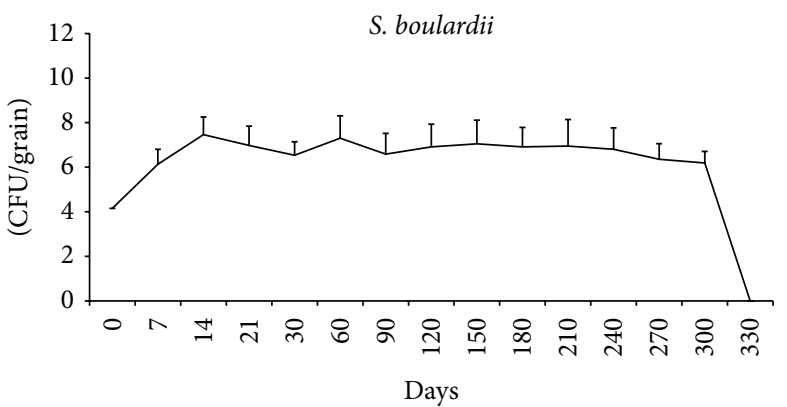

(a)

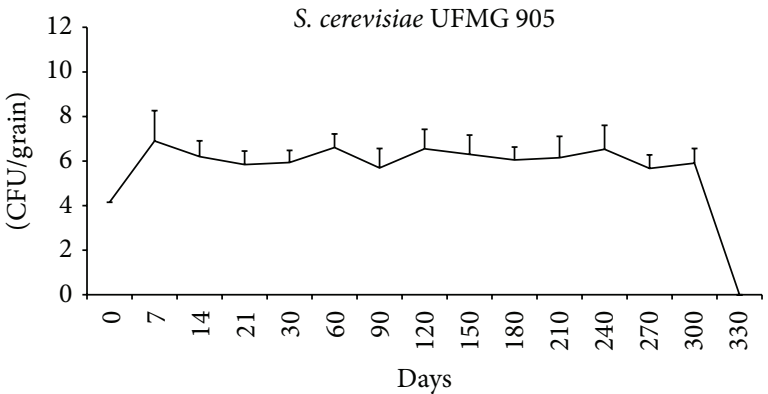

(b)

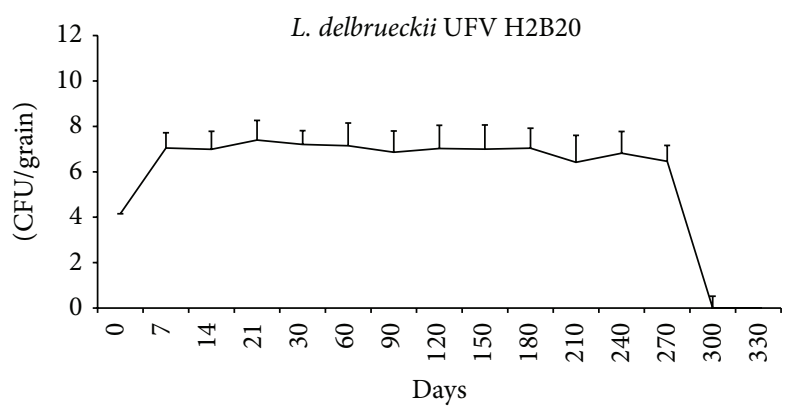

(c)

FIGURE 2: Viable cell count (CFU/Grain) of S. boulardii (a), S. cerevisiae UFMG 905 (b), and L. delbrueckii UFV H2b20 (c) during storage at $30^{\circ} \mathrm{C}$ for 330 days.

A. nomius growth were not accompanied by morphological alterations of the hyphae.

As shown above, better results for biological control of the phytopathogen were obtained when the yeasts and bacteria were used in viable form when compared to the inactivated form. As in Brazil, grains are generally stored during a mean period of about six months, and it was important to evaluate the evolution of viable population levels of the yeasts and bacteria after their inoculation onto the surface of peanuts grains during a simulated storage. Figure 2 shows that high levels of viable cells were maintained at least until 300 days after sprinkling of the three microorganisms.

Aflatoxin production by $A$. parasiticus was analyzed in the presence of each yeast and bacterium alone or in pair combinations. In the first situation, only the yeasts caused a significant reduction in aflatoxin production (Table 2), with statistically similar effects for S. cerevisiae UFMG 905 (72.8\%) and S. boulardii $(65.8 \%)$.

When inoculated in pairs, all combinations significantly reduced aflatoxin production by $A$. parasiticus (Table 3 ). Interestingly, the best result was obtained with the coinoculation of S. boulardii and L. delbrueckii (96.1\%). This synergistic effect between yeast and the Lactobacillus was not observed in the combinations between S. boulardii and S. cerevisiae (71.1\%) or L. delbrueckii and S. cerevisiae UFMG 905 (66.7\%). Similar results were obtained by Prado et al. [6] when they used two yeasts pertaining to the Saccharomycopsis genus (S. schoenii and S. crataegensis) as biological control agents. These yeasts were able to reduce $A$. parasiticus production of aflatoxin $B_{1}$ and $G_{1}$ in peanuts. These results suggest that biological control with selected microorganisms could reduce
TABLE 2: Mean aflatoxin $(\mu \mathrm{g} / \mathrm{kg})$ production by A. parasiticus IMI 242695 incubated for seven days at $30^{\circ} \mathrm{C}$ in peanut grains cultivar IAC Caiapó and perceptual reduction of aflatoxin induced by $S$. boulardii, S. cerevisiae UFMG 905, and L. delbrueckii UFV H2b20. $\mathrm{AP}=$ A. parasiticus.

\begin{tabular}{lcc}
\hline Assays & Average $^{1}$ S.D. & Reduction (\%) \\
\hline Control (AP) & $36,695.7 \mathrm{a} \pm 14,920.8$ & - \\
S. boulardii $\times$ AP & $12,538.9 \mathrm{~b} \pm 9,731.9$ & 65.8 \\
S. cerevisiae $\times$ AP & $9,981.8 \mathrm{~b} \pm 2,244.4$ & 72.8 \\
L. delbrueckii $\times$ AP & $34,265.6 \mathrm{a} \pm 6,184.2$ & 6.6 \\
\hline
\end{tabular}

${ }^{1}$ Different letters indicate significant differences according to Tukey's test $(P<0.05) ;$ S.D. $=$ standard deviation.

not only the spore dispersion but also the production of mycotoxins by phytopathogens in stored grains.

Reddy et al. [25] used three bacterial species (Rhodococcus erythropolis, Bacillus subtilis and Pseudomonas fluorescens) for biological control of A. flavus and observed that $R$. erythropolis completely inhibited phytopathogen growth and, as a consequence, its aflatoxin $B_{1}$ production. The other microorganisms reduced mycelium growth in a range of 65 to $74 \%$ and aflatoxin production from $39 \%$ to $65 \%$. The authors also noted that the inhibitory activity is likely due to a chemical antagonistic extracellular substance produced by the bacteria. Prado et al. [19] tested S. cerevisiae YEF 186 as an A. parasiticus antagonist in two peanut cultivars (IAC Runner and IAC Caiapó) with two different incubation times (seven and fourteen days) and two different inoculation sequences (yeast inoculated simultaneously or three hours before 
TABLE 3: Mean aflatoxin ( $\mu \mathrm{g} / \mathrm{kg}$ ) production by A. parasiticus IMI 242695 incubated for seven days at $30^{\circ}$ C in peanut grains cultivar IAC Caiapó and perceptual reduction of aflatoxin induced by combinations of S. cerevisiae UFMG 905, S. boulardii, and L. delbrueckii UFV H2b20. AP = A. parasiticus.

\begin{tabular}{lcc}
\hline Assays & Average $^{1}$ deviation & Reduction (\%) \\
\hline Control (AP) & $15,187.2 \mathrm{a} \pm 3,957.0$ & - \\
L. delbrueckii + S. cerevisiae $\times$ AP & $5,062.1 \mathrm{~b} \pm 3,695.0$ & 66.7 \\
S. boulardii + S. cerevisiae $\times$ AP & $4,389.4 \mathrm{~b} \pm 334.7$ & 71.1 \\
S. boulardii + L. delbrueckii $\times$ AP & $589.4 \mathrm{c} \pm 516.6$ & 96.1 \\
\hline
\end{tabular}

${ }^{1}$ Different letters indicate significant differences according to Tukey's test $(P<0.05)$.

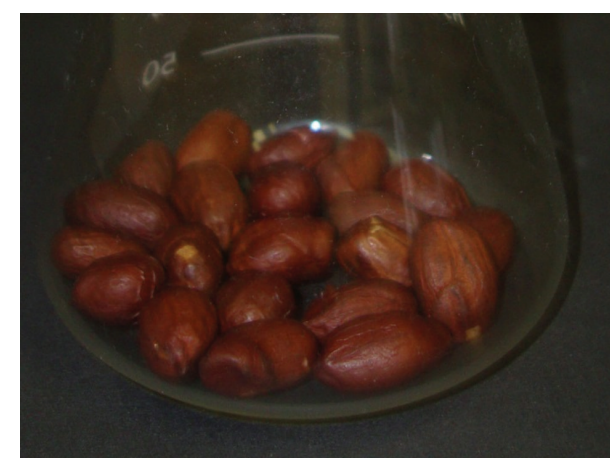

(a)

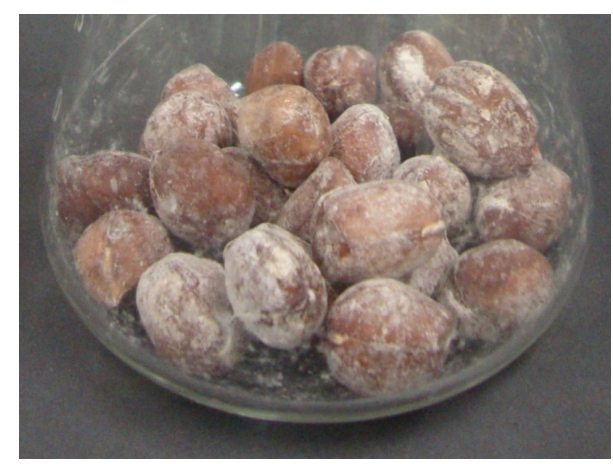

(c)

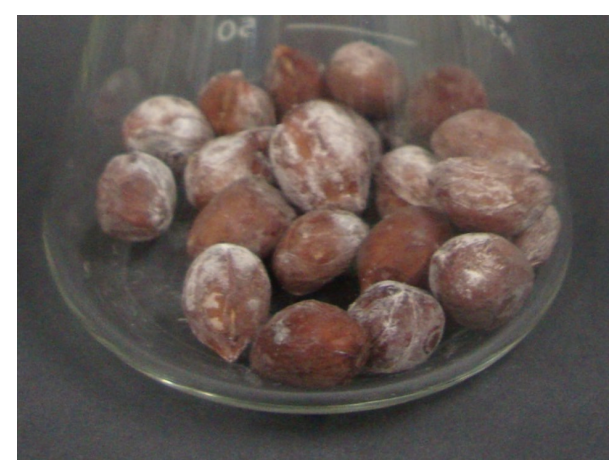

(b)

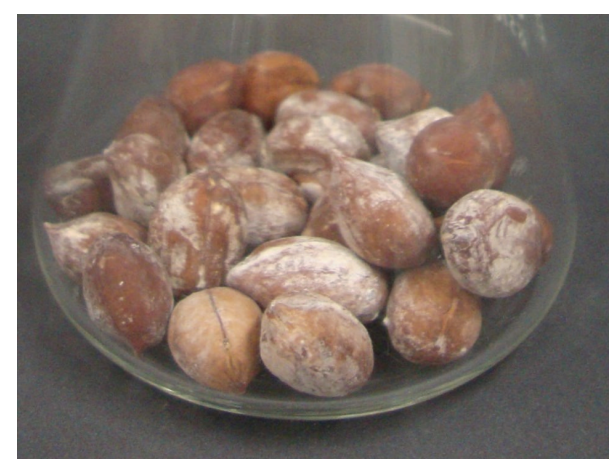

(d)

FIGURE 3: Erlenmeyer flasks with $15 \mathrm{~g}$ of autoclaved peanuts cultivar IAC caiapó inoculated with (a) negative control, only $5 \mathrm{~mL}$ of $0.1 \%$ Tween 80; (b) S. boulardii $\left(2.5 \mathrm{~mL}\right.$ at $10^{8}$ cells $/ \mathrm{mL}$ plus $2.5 \mathrm{~mL}$ of $0.1 \%$ Tween 80$)$, (c) S. cerevisiae UFMG $905\left(2.5 \mathrm{~mL}\right.$ a $10^{8}$ cells $/ \mathrm{mL}$ plus $2.5 \mathrm{~mL}$ of $0.1 \%$ Tween 80$)$, (d) L. delbrueckii UFV H2b20 (2.5 mL at $10^{8}$ cells/mL plus $2.5 \mathrm{~mL}$ of $0.1 \%$ Tween 80$)$ incubated at $30^{\circ} \mathrm{C}$ for 330 days.

the pathogen). The authors found that the best reduction of aflatoxin $\mathrm{B}_{1}(74.4 \%)$ was obtained after seven days and when the yeast was inoculated before the pathogen. The authors suggested that this reduction was probably due to aflatoxin adhesion to the yeast cell wall or to aflatoxin degradation by the yeast, and this is probably a way of reduction observed in this study. Gerbaldo et al. [26] evaluated the antifungal activities and aflatoxin $B_{1}$ reduction promoted by two Lactobacillus species (L. rhamnosus L60 and L. fermentum L23) with known probiotic activities. The Lactobacillus strains were tested against ten aflatoxigenic Aspergillus strains (nine A. flavus strains and one $A$. parasiticus). They found that Lactobacillus L60 and L23 inhibited the mycelia growth of all Aspergillus strains tested and promoted a reduction in aflatoxin production from 73 to $99 \%$. They also suggested three possible mechanisms to explain the effect: (1) aflatoxin degradation by enzymes from Lactobacillus, (2) competition for space or nutrients, or (3) absorption of aflatoxin onto the cell walls of the Lactobacillus.

Concluding, results of the present study showed that candidate microorganisms for biological control able to reduce the production of spores by aflatoxigenic fungi are more effective in a viable form than in an inactivated form. Additionally, the candidates tested here showed a high capacity to remain viable in high population levels even 300 days after their inoculation on the peanuts grains, which is an important property since in Brazil, the mean storage time for grains is of approximately six months. An interesting characteristic observed was that the tested microorganisms did not produce any apparent harm to the peanuts, and on the contrary, the microbial biofilm gave the grains an appearance similar to salted peanuts (Figures 3(a)-3(d)). 
Another advantage of probiotics is that their commercial use in the food industry is not restricted by legislation as is the case with other microorganisms. Finally, the most important effect observed with the sprinkling of the tested microorganisms was the considerable reduction of aflatoxin production by $A$. parasiticus, especially when the combination of $S$. boulardii and L. delbrueckii H2b20 was used. Overall, these data suggest that the food industries could use the proposed method as an alternative treatment to control the dispersion and aflatoxin production by phytopathogen, remembering that beyond protection during storage, the method could provide an additional probiotic effect in the digestive tract of consumers after ingestion of the treated grains. However, more studies are needed to clarify the possible impact that lactic acid bacteria and yeasts added to reduce aflatoxins could have on the organoleptic characteristics of the products as well as the exact mechanisms responsible for the reduction of the aflatoxin contents.

\section{Conflict of Interests}

The authors declare that there is no conflict of interests regarding the publication of this paper.

\section{Acknowledgments}

This work was supported by grants from the Conselho Nacional de Desenvolvimento Científico e Tecnológico (CNPq) and the Fundação de Amparo à Pesquisa do Estado de Minas Gerais (FAPEMIG). The authors thank Cristiane Martins Coelho for her technical assistance.

\section{References}

[1] D. J. Bertioli, G. Seijo, F. O. Freitas, J. F. M. Valls, S. C. M. LealBertioli, and M. C. Moretzsohn, "An overview of peanut and its wild relatives," Plant Genetic Resources: Characterisation and Utilisation, vol. 9, no. 1, pp. 134-149, 2011.

[2] M. S. Oliveira, G. Prado, F. M. Abrantes, L. G. Santos, and T. Veloso, "Incidência de aflatoxinas, desoxinivalenol e zearalenona em produtos comercializados em cidades do estado de Minas Gerais no período de 1998-2000," Revista do Instituto Adolfo Lutz, vol. 61, pp. 1-6, 2002.

[3] D. B. Rodríguez-Amaya and M. Sabino, "Mycotoxin research in Brazil: the last decade in review," Brazilian Journal of Microbiology, vol. 33, no. 1, pp. 1-18, 2002.

[4] A. Kwiatkowski and A. P. F. Alves, "Importância da detecção e do controle de aflatoxinas em alimentos," SaBios-Revista de Saúde e Biologia, vol. 2, pp. 45-54, 2007.

[5] S. Arzandeh, J. Selamat, and H. Lioe, "Aflatoxin in raw peanut kernels marketed in Malaysia," Journal of Food and Drug Analysis, vol. 18, no. 1, pp. 44-50, 2010.

[6] G. Prado, M. S. Oliveira, A. P. A. Moreira, A. S. Lima, R. A. Souza, and M. C. Alves, "Determinação de aflatoxina $B_{1} \mathrm{em}$ pimenta (Piper nigrum L.) e orégano (Origanum vulgare L.) por cromatografia em camada delgada e densitometria," Química Nova, vol. 31, no. 3, pp. 514-517, 2008.

[7] Y.-C. Lin, P. M. Schlievert, M. J. Anderson et al., "Glycerol monolaurate and dodecylglycerol effects on Staphylococcus aureus and toxic shock syndrome toxin-1 in vitro and in vivo," PLoS ONE, vol. 4, no. 10, Article ID e7499, 2009.

[8] M. S. Rodríguez, V. Ramos, and E. Agulló, "Antimicrobial action of chitosan against spoilage organisms in precooked pizza," Journal of Food Science, vol. 68, no. 1, pp. 271-274, 2003.

[9] K. L. Strandberg, M. L. Peterson, Y.-C. Lin, M. C. Pack, D. J. Chase, and P. M. Schlievert, "Glycerol monolaurate inhibits Candida and Gardnerella vaginalisin vitro and in vivo but not Lactobacillus," Antimicrobial Agents and Chemotherapy, vol. 54, no. 2, pp. 597-601, 2010.

[10] FAO/WHO (Food and Agriculture Organization/World Health Organization) Working Group, Guidelines for the Evaluation of Probiotics in Food, FAO/WHO, London, UK, 2002.

[11] P. H. Shetty and L. Jespersen, "Saccharomyces cerevisiae and lactic acid bacteria as potential mycotoxin decontaminating agents," Trends in Food Science and Technology, vol. 17, no. 2, pp. 48-55, 2006.

[12] V. Miteva, I. Ivanova, I. Budakov et al., "Detection and characterization of a novel antibacterial substance produced by a Lactobacillus delbrueckii strain 1043," Journal of Applied Microbiology, vol. 85, no. 3, pp. 603-614, 1998.

[13] E. Røssland, T. Langsrud, P. E. Granum, and T. Sørhaug, "Production of antimicrobial metabolites by strains of Lactobacillus or Lactococcus co-cultured with Bacillus cereus in milk," International Journal of Food Microbiology, vol. 98, no. 2, pp. 193-200, 2005.

[14] F. C. P. Tiago, F. S. Martins, E. L. S. Souza et al., "Adhesion to the yeast cell surface as a mechanism for trapping pathogenic bacteria by Saccharomyces probiotics," Journal of Medical Microbiology, vol. 61, no. 9, pp. 1194-1207, 2012.

[15] S. V. Generoso, M. Viana, R. Santos et al., "Saccharomyces cerevisiae strain UFMG 905 protects against bacterial translocation, preserves gut barrier integrity and stimulates the immune system in a murine intestinal obstruction model," Archives of Microbiology, vol. 192, no. 6, pp. 477-484, 2010.

[16] F. S. Martins, R. M. D. Nardi, R. M. E. Arantes, C. A. Rosa, M. J. Neves, and J. R. Nicoli, "Screening of yeasts as probiotic based on capacities to colonize the gastrointestinal tract and to protect against enteropathogen challenge in mice," Journal of General and Applied Microbiology, vol. 51, no. 2, pp. 83-92, 2005.

[17] F. S. Martins, A. C. P. Rodrigues, F. C. P. Tiago et al., "Saccharomyces cerevisiae strain 905 reduces the translocation of Salmonella enterica serotype Typhimurium and stimulates the immune system in gnotobiotic and conventional mice," Journal of Medical Microbiology, vol. 56, no. 3, pp. 352-359, 2007.

[18] L. M. Santos, M. M. Santos, H. P. S. Silva, R. M. E. Arantes, J. R. Nicoli, and L. Q. Vieira, "Monoassociation with probiotic Lactobacillus delbrueckii UFV-H2b20 stimulates the immune system and protects germfree mice against Listeria monocytogenes infection," Medical Microbiology and Immunology, vol. 200, no. 1, pp. 29-38, 2011.

[19] G. Prado, J. E. G. Cruz Madeira, V. A. D. Morais et al., "Reduction of aflatoxin B1 in stored peanuts (Arachis hypogaea L.) using Saccharomyces cerevisiae," Journal of Food Protection, vol. 74, no. 6, pp. 1003-1006, 2011.

[20] L. M. Valente Soares and D. B. Rodriguez-Amaya, "Survey of aflatoxins, ochratoxin A, zearalenone and sterigmatocystin in Brazilian foods by using multitoxin thin-layer chromatographic methods," Journal of the Association of Official Analytical Chemists, vol. 73, pp. 22-26, 1989. 
[21] J. R. Tagg, A. S. Dajani, and L. W. Wannamaker, "Bacteriocins of gram positive bacteria," Bacteriological Reviews, vol. 40, no. 3, pp. 722-756, 1976.

[22] A. A. Onilude, O. E. Fagade, M. M. Bello, and I. F. Fadahunsi, "Inhibition of aflatoxin-producing aspergilli by lactic acid bacteria isolates from indigenously fermented cereal gruels," African Journal of Biotechnology, vol. 4, no. 12, pp. 1404-1408, 2005.

[23] D. J. Bueno, J. O. Silva, G. Oliver, and S. N. González, "Lactobacillus casei CRL 431 and Lactobacillus rhamnosus CRL 1224 as biological controls for Aspergillus flavus strains," Journal of Food Protection, vol. 69, no. 10, pp. 2544-2548, 2006.

[24] R. Muñoz, M. E. Arena, J. Silva, and S. N. González, "Inhibition of mycotoxin-producing Aspergillus nomius vsc 23 by lactic acid bacteria and Saccharomyces cerevisiae," Brazilian Journal of Microbiology, vol. 41, no. 4, pp. 1019-1026, 2010.

[25] K. R. N. Reddy, C. R. Raghavender, B. N. Reddy, and B. Salleh, "Biological control of Aspergillus flavus growth and subsequent aflatoxin $\mathrm{B}_{1}$ production in sorghum grains," African Journal of Biotechnology, vol. 9, no. 27, pp. 4247-4250, 2010.

[26] G. A. Gerbaldo, C. Barberis, L. Pascual, A. Dalcero, and L. Barberis, "Antifungal activity of two Lactobacillus strains with potential probiotic properties," FEMS Microbiology Letters, vol. 332, no. 1, pp. 27-33, 2012. 

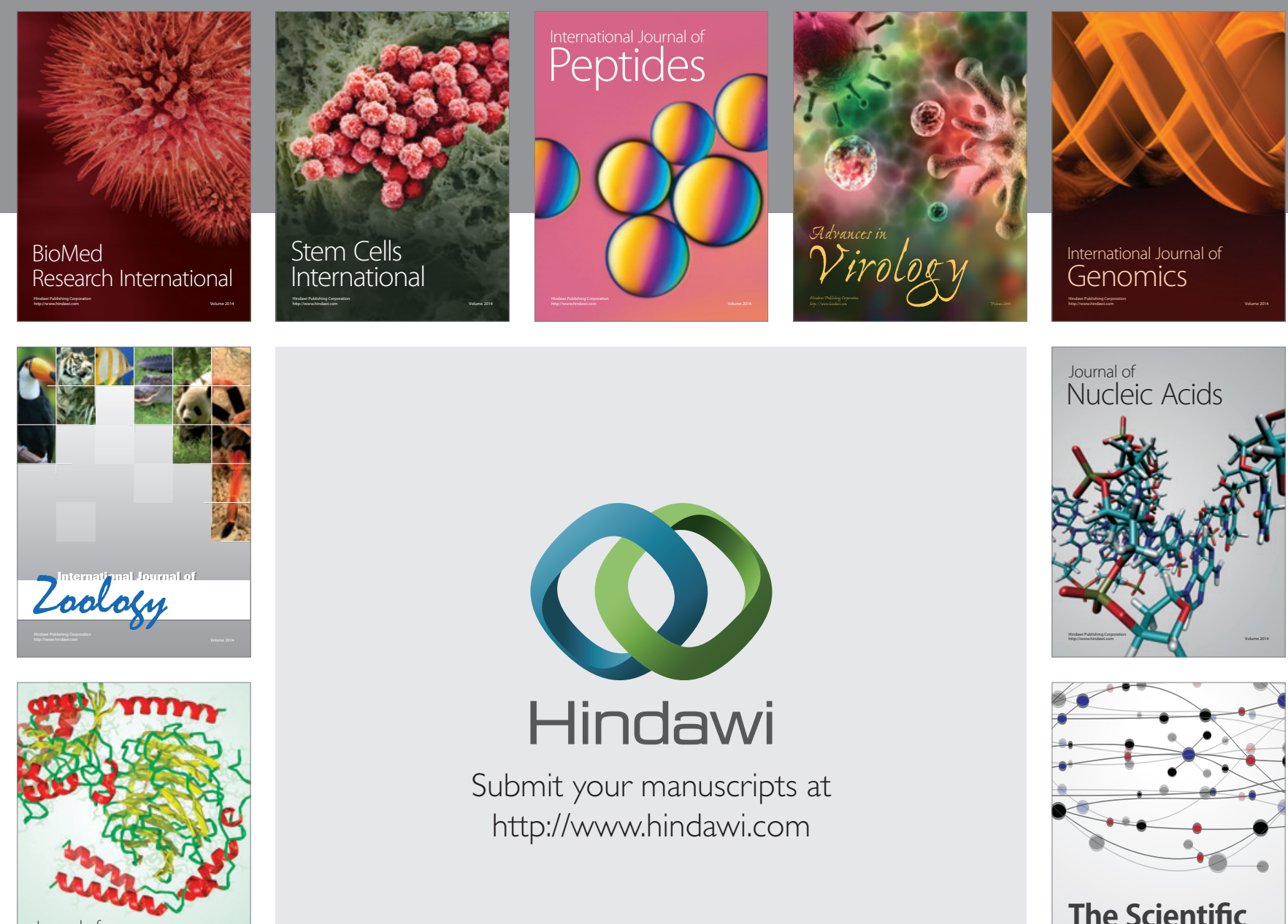

Submit your manuscripts at

http://www.hindawi.com

Journal of
Signal Transduction
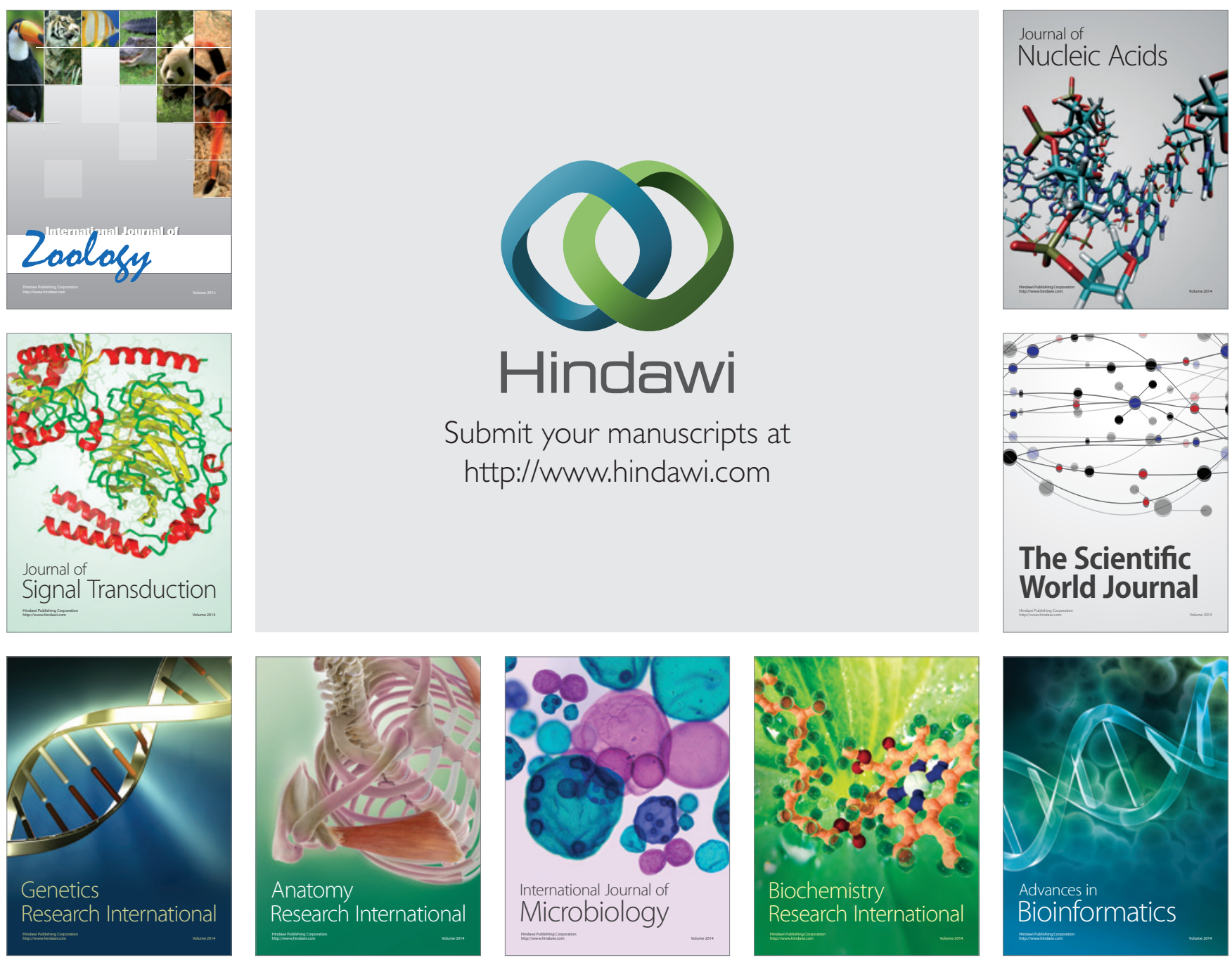

The Scientific World Journal
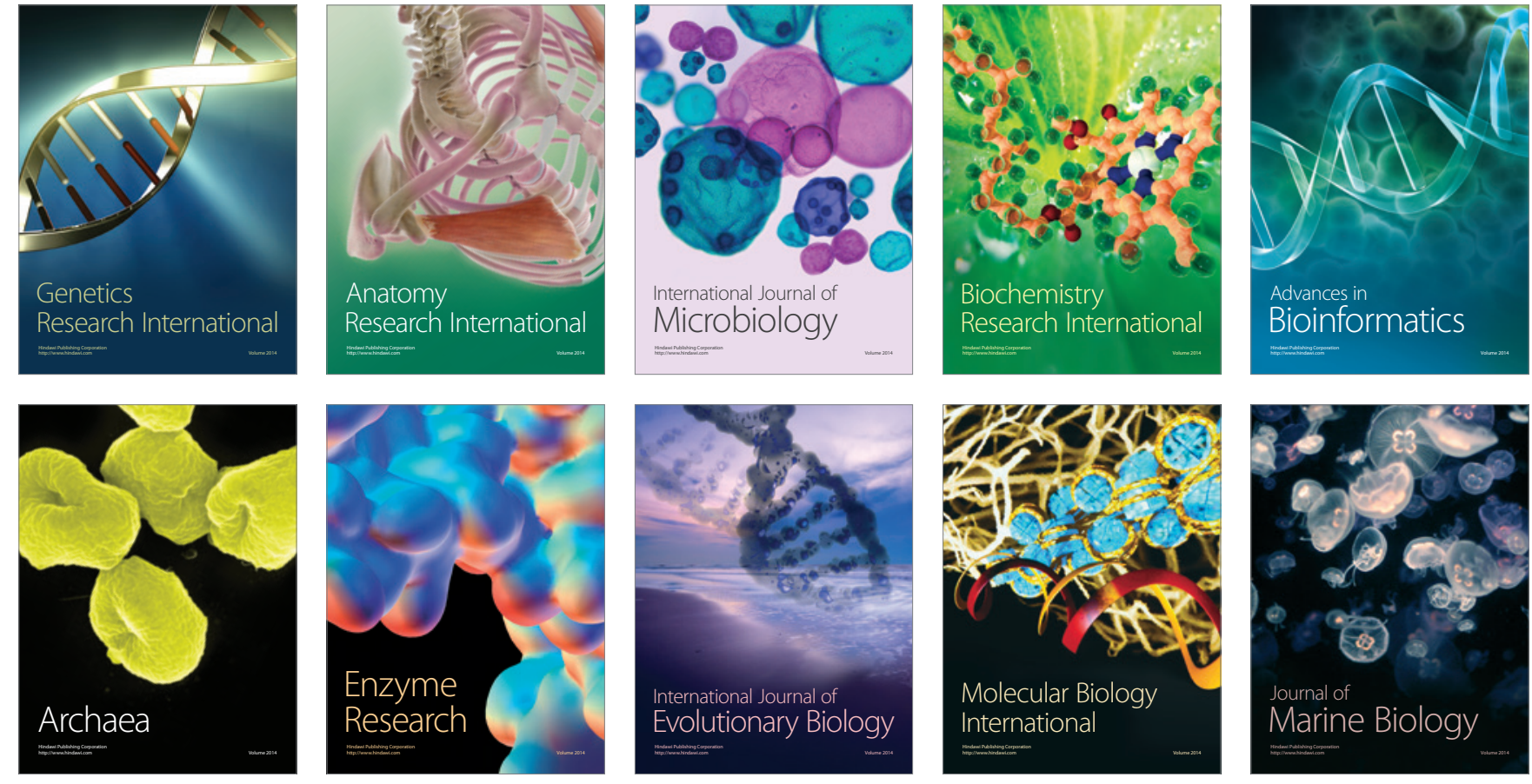